\title{
Warm up
}

This edition is full of contrast. Our editorials focus on the Olympics and some of the factors that will come into play when the best athletes in the world converge at that great spectacle in Atlanta. At the other end of the exercise spectrum we publish a review article focusing on exercise promotion.

Empirically we would all support efforts to promote physical activity but the health and exercise promotion industry is often rich in rhetoric but short on fact. This review by Hillsdon and Thorogood presents a great challenge to us all. They present a very clear evidence based message on how to promote physical activity which is not perhaps the message we would like to hear. Some may argue with their criticism of exercise prescription

\section{Olympic dream}

In the next few weeks children all over the world will be competing in their own Olympics. Races will be run in playgrounds, on beaches and parks, in barefoot and in the most expensive runners, in the latest lycra and in rags. Everyone a winner. All imagining the glorious heights, breasting the tape arms held aloft. Proudly wearing the ribbons and gold on their chest, their own national anthem echoing in their heads. Dreaming and sport are two happy companions.

The Olympics still retain their magical attraction. A happy family of sporting nations joining together in a festival of achievement. Yet almost certainly we shall witness revelations about drugs, allegations of cheating, cynical efforts at performance enhancement, and manipulation of the regulations. Science and medicine have helped explore the outer margins of performance but inevitably some of these discoveries will be abused and we schemes and the lack of British research but the message remains. It is easy to watch the Olympics on television, but a lot more difficult to take some exercise ourselves. The paper is also a timely example of how to construct a systematic review article which we would encourage all authors to follow.

One name on the new masthead of the Journal will be sadly missed. John Sutton was known to us all for his zest for life and his enthusiastic embrace of every new adventure. He died just weeks before publication of his description of cycling the Simpson desert (March 1996). His last paragraph now has particular poignancy. We include appreciations from two of his close colleagues. must all accept some of the collective blame. Medicine does not always prosper from its association with sport. Most of us became involved in sport for the same reasons that children's hearts will flutter when competing in their own Olympics. We retain that inner belief in the value of sport but we cannot put the genie back in the bottle.

Yet, just when the cynic begins to wonder if it is possible to win fairly, we witness a performance that is clearly founded on natural talent and personal commitment which restores our faith in beauty of sport and the glory of human endeavour. As I watch, in my own mind, I too will be running the 1500 metres, racing the Olympics sculling final, and punching the air as I win the cycling road race. Sometimes it's nice to believe in fairy tales.
As we approach the Games of the XXVIth Olympiad in Atlanta this July much of the country will become fascinated with sport. All sports medicine professionals involved with Olympic sports have an opportunity to take advantage of this raised profile for the good of the profession.

The International Olympic Committee (IOC) set up the IOC Medical Commission after the Tokyo Olympics in 1964 in order to combat the threat of drugs in sport. A firm stand was taken against the philosophy of winning at any cost. Following on from Olympic ideals, the basic principles of the IOC Medical Commission consist of ensuring an equal chance for everyone, the defence of ethics, and the protection of the health of athletes. The
Commission is now active in all aspects of sports and exercise medicine. In parallel with this the British Olympic Association (BOA) has become deeply involved in sports medicine and sports science. The involvement is now seen as a fundamental part of Olympism, as well as being vital the the patriotic aim of optimising the performance of our athletes at the Olympic games! The BOA is formed from the amalgamation of more than 30 Olympic sports, and our first duty is to the 1500 "passport holders" identified by all governing bodies as potential Olympians. Through the British Olympic Medical Centre, the network of Governing Body Medical Officers and specialists all over the country we provide an elite service up to and during the Olympic Games. 
Both the lofty aims of the Olympic movement and the tangible aim of winning Olympic Gold medals means that the BOA has become involved more broadly in the provision and development of sports science and medicine in Great Britain. We have a responsibility to all individuals who take part in any Olympic sport, especially the juniors who so often fail to make that difficult leap to successful senior competition. Thus it is good to see the close cooperation that has developed between the BOA, British Association of Sport and Medicine (BASM) and the National Sports Medicine Institute (NSMI). We are pushing hard together for the development of sports and exercise medicine as a specialty. The care of present and potential Olympians will be served best by full time doctors attracted to the specialty by a proper career structure.
Looking to the future the proposed Academy of Sport is likely to provide a large stimulus to change. The BOA already provides most of the services to Olympic sports that are planned for the Academy of Sport, and I hope that the Academy will enable us to provide elite services to a far larger population of athletes in co-operation with all organisations involved in sports science and medicine.

The Centenary Olympic Games and the universal appeal of the Olympic rings will increase the interest in all types of sport. It is right that we should use this goodwill and enthusiasm to further the development of sports and exercise medicine.

RICHARD BUDGETT Director of Medical Services for the British Olympic Association

\section{The Olympic Games and sports medicine}

In my view, the reawakening of modern interest in the sports sciences after the second world war can be traced to three events, all related to the Olympic Games. In this Olympic year, it is perhaps appropriate to review that history and to speculate on possible future intellectual challenges that the Olympic Games may yet pose for our profession.

The first significant event was the realisation in the 1960s that drug use in international sport was on the increase. The creation of the International Olympic Committee (IOC) Medical Committee, with the express responsibility of controlling drug use in Olympic competition, and the subsequent introduction of drug testing at the 1968 Olympic Games, focused global attention on our profession and its role in contemporary scientific issues in international sport. Besides its many other functions, this committee has more recently been responsible for the establishment of the Olympic Prize to honour individuals with a lifetime of exceptional achievement in the sports sciences. This award, to be bestowed for the first time at the 1996 Atlanta Olympic Games, will further enhance the stature of our profession before a massive global audience.

The second event was the quite dramatic rise to dominance of the eastern European countries, especially the former German Democratic Republic (GDR), in Olympic competition. During the 1968 Olympic Games, the first Games in which the GDR competed as a team separate from West Germany, their athletes won 25 medals. In the 1988 Olympic Games, athletes from that country won 102 medals, one more than the total medal count for athletes from the United States, a country with a population amost 10 -fold larger than that of the GDR. The huge social cost of such success is still being counted.

But in as much as other nations perceived that this success resulted from a more "scientific" and professional approach to sport in the GDR, so those nations with the capacity began to investigate ways in which science could be profitably applied for the enhancement of human sporting performance. Of the Commonwealth countries, Australia especially has taken the lead in these developments.

The third important factor was the holding of the 1968 Olympic Games at Mexico City. For Mexico City is sited at an altitude of $2270 \mathrm{~m}$ and never before had the
Olympic Games been held in a city so high above sea level.

This single event first exposed, on an international scale, the very real and quite embarrassing inadequacies in our knowledge of some quite basic issues in the applied sports sciences. For at that time, the real effects of medium altitude on athletic performance were simply not known. Nor had the potential health risks associated with holding Olympic competition at altitude been studied.

Challenged by this ignorance and, perhaps, by the desire to gain a competitive advantage for their athletes, most nations with capacity in the exercise sciences immediately established exercise at altitude as an urgent research priority. Many of the legendary modern physiologists were soon involved. Not unexpectedly, the British turned to the late Dr Griffiths Pugh, whose high altitude research in the early $1950 \mathrm{~s}^{1}$ is considered to be one of the most important reasons why the British were the first to reach the summit of Mount Everest in 1953.

For four weeks at the end of 1966, Pugh studied six leading British middle distance runners during a period of acclimatisation to altitude at Mexico City. He showed that, compared to performance at sea level in Britain, the athlete's times in a 3 mile $(4842 \mathrm{~m})$ running race increased by $8.5 \%$ within the first week of exposure to altitude: performance then improved somewhat but was still $5 \cdot 7 \%$ slower than sea level performance after four weeks at altitude. ${ }^{2}$ Thus even after four weeks of acclimatisation at altitude, performance in a 3 mile race was slowed by about 43 seconds in world class athletes from sea level who were unacclimatised to running at altitude. Pugh concluded that while performance improved with residence at altitude, the time it would take for full acclimatisation was a "matter of months rather than weeks. "2 $\mathrm{He}$ also expressed some concern that the heart "during and after maximum exercise at $2270 \mathrm{~m}$ is more irritable than at sea level, and it is conceivable that there might be a risk of ventricular fibrillation. " 2

This classical study sets a standard for the measurement of the ergogenic effect of a specific intervention in a tightly controlled experimental setting. Subsequent events confirmed the prediction that the endurance running events in those Games would be dominated by athletes who resided at altitude, most especially those from East Africa. Sir Roger Bannister's statement ${ }^{3}$ that it would take the competitive lifetime for an athlete born 